\title{
Pathophysiology of Cholestatic Liver Diseases: New Insights into the Mechanisms of Bile Infarct Formation
}

\section{Reham Hassan 1, 2, Abdel-latif Seddek ${ }^{2}$, Ahmed Ghallab ${ }^{1,2, *}$}

${ }^{1}$ Leibniz Research Centre for Working Environment and Human Factors at the Technical University Dortmund, Dortmund, Germany.

${ }^{2}$ Department of Forensic Medicine and Toxicology, Faculty of Veterinary Medicine, South Valley University, Qena, Egypt.

\section{Abstract}

Cholestatic liver diseases can be induced for many reasons including obstructions, e.g. by stones or tumors. An early consequence of obstructive cholestasis is the formation of bile infarcts, which refer to clusters of dead hepatocytes due to bile salt accumulation. Although these infarcts were described long time ago (in 1876 by Charcot and Gombault), the leading mechanism is still unclear. Some hypotheses suggested direct killing by accumulation of bile salts up to toxic levels. Others claim indirect cell death via immune cell infiltration and inflammatory cytokine release. However, the sequence of events leading to the formation bile infarcts are still unclear. In the recent issue of Hepatology, Ghallab and his colleagues have recorded in a time-resolved manner the key events leading to bile infarct formation and the subsequent systemic changes, using two-photon based intravital imaging. This mini-review highlights the results of this study and discuss the timeresolved events in acute and chronic cholestasis, as well as the link between biliary bile salts and hepatocyte death.

Keywords: Cholestasis; intravital imaging; bile canaliculi; bile salt toxicity; bile leakage; bile duct ligation.

Received: December 16, 2018 Accepted: December 16, $2018 \quad$ Published: December 17, 2018 *Corresponding Author: Ahmed Ghallab E-mail: Ghallab@ifado.de Citation: Hassan et al., Pathophysiology of Cholestatic Liver Diseases: New Insights into the Mechanisms of Bile Infarct Formation. SVU-IJVS 2018, 1 (2): 95-105.

Copyright: () Hassan et al. This is an open access article distributed under the terms of the creative common attribution license, which permits unrestricted use, distribution and reproduction in any medium provided the original author and source are created.

Competing interest: The authors have declared that no competing interest exists. 


\section{Introduction}

Bile is a toxic body fluid which is present in a detergent concentration in the biliary tract (Woolbright et al., 2015). It serves multiple functions, including (i) fat digestion within the intestinal tract via its detergent action, (ii) excretion of most of the harmful xenobiotics, bilirubin and bile salts, and (iii) elimination of cholesterol (Boyer, 2013). Thus, the biliary tree can be considered as a drainage system of most harmful molecules, particularly bile salts. This raise the question, what are the consequences of bile leakage in case of cholestatic liver diseases? Cholestasis can be mimicked in experimental animals by ligation of the common bile duct at the position between the gallbladder and the duodenum (Tag et al., 2015). This procedure recapitulates at least some features of obstructive cholestatic liver disease progression in human. In the acute stage after bile duct ligation (days 1-3), bile salt concentrations increase sharply in the biliary tree (Ghallab et al., 2018). This coincide with development of clusters of dead hepatocytes, a lesion named 'bile infarcts' (Figure 1). In the chronic phase, bile infarcts are not any longer seen, but ductular reaction and periportal fibrosis develop (Ghallab et al., 2018) (Figure 1). Although bile infarcts are described long time ago in obstructive cholestasis (Rolleston, 1905), the exact leading mechanism is still unclear. This can partly be because of the lack of technologies that allow direct spatio-temporal visualization of bile transport. In this minireview, we focus on the advantages of intravital imaging in getting new insights into cholestatic liver disease progression.

\section{Bile salt toxicity}

Bile salts are amphipathic molecules that are synthesized in hepatocytes from cholesterol in a series of enzymatic reactions. This is initiated by CYP7A1 enzyme and occurs predominantly in the pericentral compartment of the liver lobule (Fickert and Wagner, 2017, Norlin and Wikvall, 2007, Russell, 2003). Following conjugation in hepatocytes, bile salts are secreted into bile canaliculi, mainly via the bile salt export pump (BSEP). From there, bile flux occurs towards the downstream interlobular and large bile ducts and finally drains into the duodenum via the common bile duct (Fickert and Wagner, 2017). Following deconjugation and enzymatic modifications by gut microbiota, approximately $95 \%$ of the formed secondary bile salts are reabsorbed in the terminal ileum and reach the liver back via the portal vein (de Aguiar Vallim et al., 2013, Schneider et al., 2018). The concentrations of bile salts differ in various compartments of the body. In the systemic blood, the total bile salt concentration is approximately 2-8 $\mu \mathrm{M}$. In hepatocytes, bile salt concentrations are less than $50 \mu \mathrm{M}$. In contrast, the biliary concentration of bile salts is approximately $20-40 \mathrm{mM}$, which is further concentrated in the gallbladder up to $100 \mathrm{mM}$ ( Fickert and Wagner, 2017). Based on in vitro experiments, bile salts display concentration dependent effects (Jansen et al., 2017) (Table 1). At concentrations below $25 \mu \mathrm{M}$, they act as signaling molecules (Chen et al., 2001, Schreuder et al., 2010). At concentrations between 50-200 $\mu \mathrm{M}$, they may induce apoptosis (Schoemaker et al., 2004). At concentrations around $200 \mu \mathrm{M}$, they may induce pro-inflammatory genes (Allen et al., 2011). At concentrations between 200-2000 $\mu \mathrm{M}$, they may trigger necrosis (Woolbright et al., 2015), and at higher concentrations they act as detergents (Woolbright et al., 2015). 


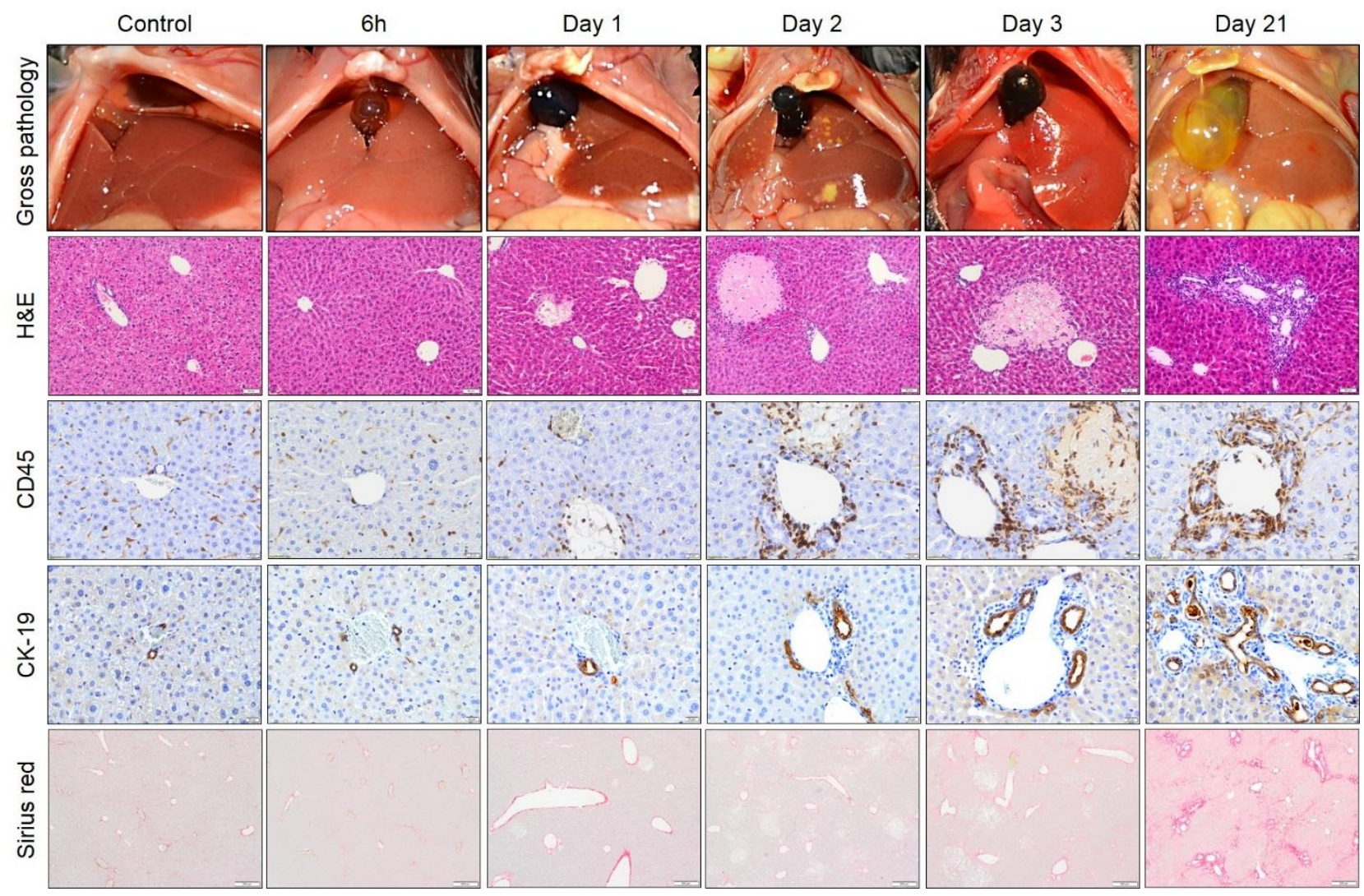

Figure 1. Pathogenesis of obstructive cholestasis following common bile duct ligation (BDL). The gross pathology shows accumulation of dark toxic bile in the acute stage (>day 3) and white/yellow bile in the chronic phase (day 21) after BDL. The HE staining shows bile infarcts on days 1 to 3 post BDL. In the chronic phase, periportal immune cell infiltration (CD45), ductular reaction (CK-19) and fibrosis (Sirius red) can be seen. [Source: Ghallab et al., 2018].

In healthy livers, cholangiocytes are protected against the detergent concentrations of bile salts via several mechanisms: (i) bile salts in bile are packed into mixed micelles with phospholipids and cholesterol, which help to neutralize bile salt toxicity (Coleman et al., 1979, Fickert and Wagner, 2017, Jansen et al., 2017, Puglielli et al., 1994, Schoemaker et al., 2004). (ii) The biliary $\mathrm{HCO3}^{-}$umbrella. Penetration of bile salts into cholangiocytes occurs at acidic $\mathrm{pH}$, because it depends on their protonation (Beuers et al., 2012, Chang et al., 2016, Fickert and Wagner, 2017, Jansen et al., 2017). Thus, secretion of $\mathrm{HCO}^{3-}$ by cholangiocytes to their apical membrane help in alkalizing the $\mathrm{pH}$ leading to deprotonation of bile salts, and thereby protection of cholangiocytes. (iii) At the canalicular level, hepatocytes are protected against bile salt leakage by tight junctions and pericanalicular cytoskeleton (Das et al., 2009, Jansen et al., 2017, Liu et al., 2015, Masyuk et al., 2001). These data open the following questions: what happen in case of breach of these natural barriers? How these toxic/detergent bile salt concentrations will affect the neighboring parenchyma? What are the systemic consequences in case of bile leakage into blood? 
Table. 1. Concentration-dependent effects of bile salts [Source: modified from Jansen et al., 2017].

\begin{tabular}{ccc}
\hline $\begin{array}{c}\text { Concentration } \\
{[\boldsymbol{\mu M}]}\end{array}$ & Effect & Reference \\
\hline$<25$ & FXR- and TGR5-signaling & Chen et al., 2001, chreuder et \\
$50-200$ & apoptosis & Schoemaker et al., 2004 \\
200 & Pro-inflammatory genes & Allen et al., 2011 \\
$200-2000$ & necrosis & Woolbright et al., 2015 \\
$>2000$ & Detergent action & Woolbright et al., 2015 \\
\hline
\end{tabular}

\section{Intravital two-photon based imaging reveals mechanism of bile infarct formation}

Bile infarcts refer to damage of the liver parenchyma due to bile leakage in case of obstructive cholestasis. This was described more than a century ago by Charcot and Gombault (Rolleston, 1905). However, the mechanism behind this damage, also called Charcot-Gombault necrosis, is not yet clear. Several hypotheses were previously published with the goal to illustrate the mechanism of hepatocyte death in cholestatic livers (Cai and Boyer, 2018). This includes (i) induction of hepatocyte necrosis or apoptosis via accumulation of bile salts

A recent study by Ghallab and colleagues (Ghallab et al., 2018) have investigated the sequence of events that precede and follow the formation of bile infarcts in mice with obstructive cholestasis. A key event that triggers bile infarct formation is the rupture of the apical hepatocyte membrane. A central technique in this study is two-photon based intravital imaging. Combination of the infrared excitation laser, broad spectrum wavelength (680-1080 $\mathrm{nm})$, long-distance objectives with high numerical apertures, and sensitive detectors provided by two-photon microscopy, together with good anesthesia above certain thresholds (Schoemaker et al., 2004, Woolbright et al., 2015). (ii) Other publications illustrated that hepatocyte death in cholestasis occurs indirectly as a consequence of immune cell infiltration, and inflammatory cytokine release (Allen et al., 2011, Cai et al., 2017). This hypothesis was supported by decreased bile infarct formation in bile duct-ligated mice where the inflammatory response is mitigated due to depletion of inflammatory cells, gene knockout of cytokine or adhesion molecules or drug treatments (Gujral et al., 2003). Although these arguments which support these investigations, detailed spatio-temporal events that lead to bile infarct formation in cholestatic livers are still to be elucidated.

and excellent animal preparation allow to perform long-term intravital imaging of intact livers (Reif et al., 2017). Fast recordings in the millisecond range are also possible. The image resolution is close to 200 $\mathrm{nm}$, which is enough to image also at the subcellular level (Ghallab and Hengstler., 2018, Ghallab et al., 2018, Jansen et al., 2017, Koppert et al., 2018, Reif et al., 2017). Applying this technology in imaging bile salt transport in the liver during the acute stage after bile duct ligation (days 1-3) (Ghallab et al., 2018) allowed to record the following sequence of events: (i) firstly, individually 
dispersed hepatocytes loss their mitochondrial membrane potential; (ii) this is followed by rupture of the apical hepatocyte membrane, and (iii) flooding of the neighboring hepatocyte with bile, which leads to (iv) cell death; (v) the dead cells create a biliary-sinusoidal shunts leading to release of bile into the neighboring sinusoids; (vi) this triggers a domino effect of further death events of neighboring hepatocytes leading to formation of clusters of dead cells (the bile infarcts); (vii) formation of bile infarcts is followed by immune cell infiltration, particularly neutrophils (Figure 2). Of course, this does not mean that immune cell infiltration is not relevant in the pathogenesis of acute cholestasis, but this intravital imaging (Ghallab et al., 2018) reveals that they are not involved in the initial event. Infiltration of immune cells might aggravate the initial damage triggered by rupture of the apical hepatocyte membrane. These data suggest that the limited number of hepatocytes which are killed in the acute phase of obstructive cholestasis serve to reduce bile salt concentrations in the biliary tree. The lost hepatocytes can be efficiently replaced within few days by the enormous regeneration capacity of the liver (Ghallab et al., 2016, Leist et al., 2017, Schliess et al., 2014).

A.

B.
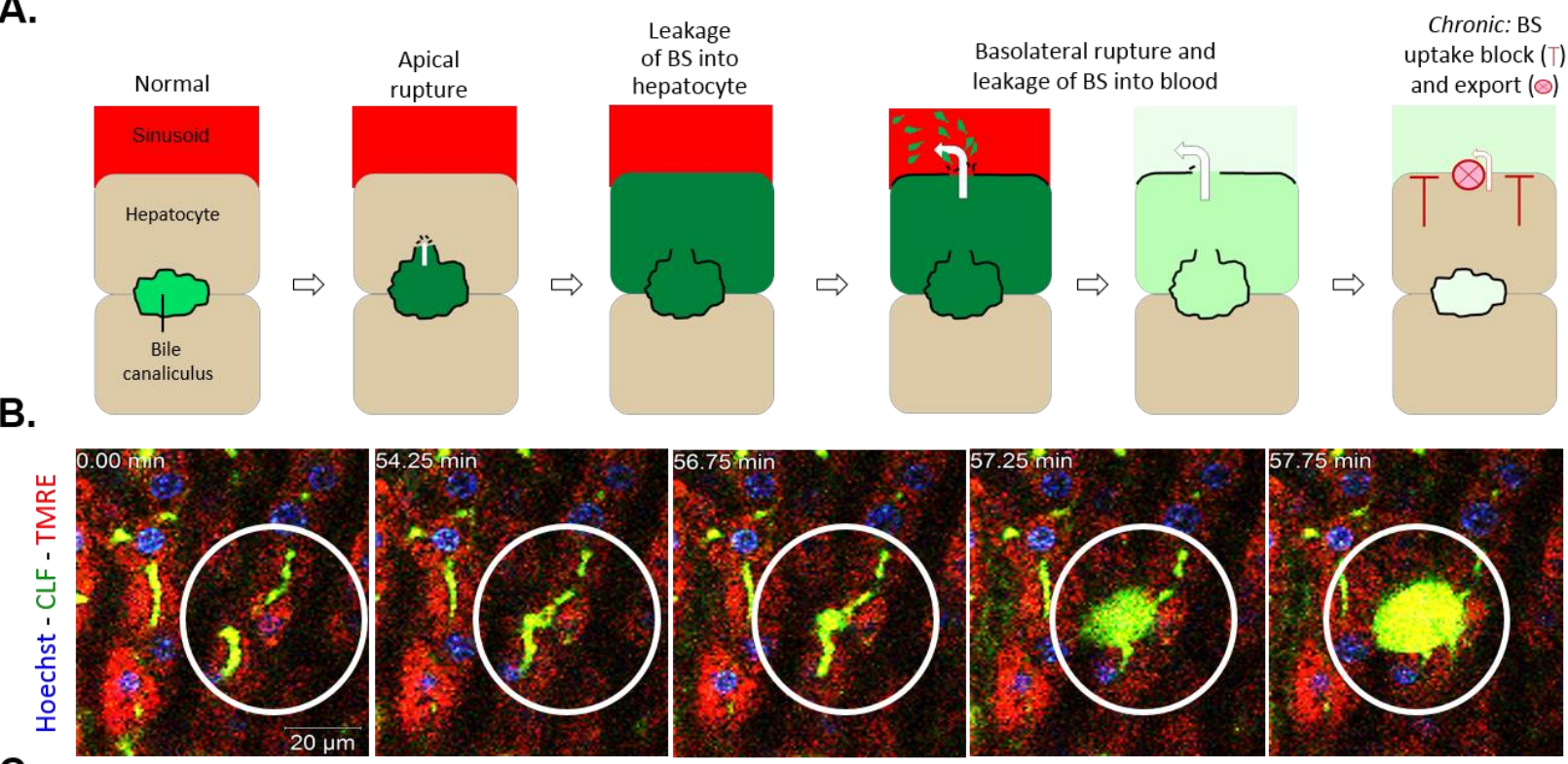

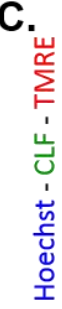
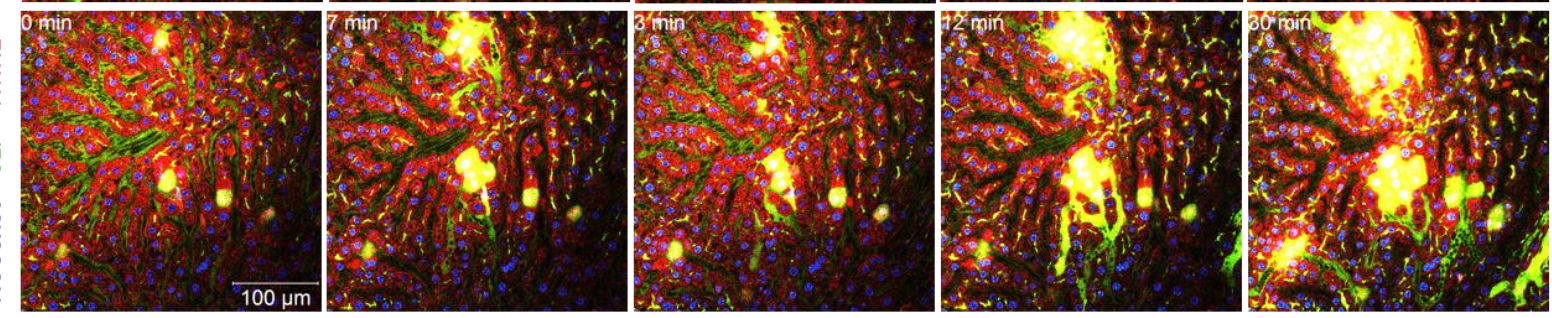

Figure 2. Apical membrane rupture is the key event triggering bile infarct formation. A\&B. A schedule and stills of intravital imaging recording the events before and after rupture of the apical membrane on day one after bile duct ligation. C. Domino effect of bile infarct formation starting from individually dispersed bile flooded cells. [Source: modified from Ghallab et al., 2018]. 
In the chronic phase after bile duct ligation (> day 21), there is no bile infarcts, and the concentrations of bile salts in the biliary tree decrease to control levels or even less (Ghallab et al., 2018). This is because several adaptive mechanisms are established by the liver at this stage to prevent accumulation of the toxic bile salts. This includes adaptation at the hepatocyte and at the biliary tree levels. At the hepatocyte level. Chronic cholestasis leads to downregulation of the basolateral uptake transporters (NTCP, Oatp) (Geier et al., 2007, Ghallab et al., 2018, Slitt et al., 2007). This can be directly seen by the strongly reduced uptake of green fluorescent bile salt analogues on day 21 after bile duct ligation (Ghallab et al., 2018). In addition, the efflux transporters, MRP3 and MRP4, are strongly upregulated at the sinusoidal membrane, allowing the transport of bile salts from hepatocytes to blood (Geier et al., 2007, Ghallab et al., 2018). Furthermore, CYP7A1 expression in hepatocytes, the key enzyme in bile salt synthesis, is reported to be downregulated in cholestatic patients (Schaap et al., 2009). At the biliary tree level. The biliary tree can be organized into three main topological domains: the large and common bile ducts, the interlobular bile ducts, and the canalicular network (Jansen et al., 2017). (i) The large bile ducts are distinguished by having diameters more than $100 \mu \mathrm{m}$. In obstructive cholestasis these large ducts respond by further increase of their diameters, allowing to accommodate the large volume of bile (Jansen et al., 2017). (ii) The interlobular bile ducts are defined by having diameters between 10-100 $\mu \mathrm{m}$. In cholestasis, these ducts undergo extensive remodeling which leads to branching and corrugation; a process named ductular reaction (Jansen et al., 2017). This occurs in harmony with upregulation of the sodium dependent transporter, ABST, and the basolateral organic solute transporter Ost $\alpha / \beta$ in cholangiocytes. These transporter changes allow to remove bile salts from the biliary tree and efflux into the peri-biliary plexus; a process named cholehepatic shunt (Geier et al., 2007, Jansen et al., 2017, Slitt et al., 2007). Thus, remodeling of the interlobular bile ducts allows to maximize the bile resorption capacity via the cholehepatic shunt. (iii) The Bile canaliculi are the most upstream domain of the biliary tree formed between the apical membranes of two neighboring hepatocytes. In healthy livers, the diameter of bile canaliculi is approximately $1 \mu \mathrm{m}$ (Jansen et al., 2017). In contrast, in obstructive cholestasis, the diameter increases up to $10-20 \mu \mathrm{m}$ (Ghallab et al., 2018). However, the relevance of these canalicular alterations was not clear. A recent study by Gupta et al. illustrated blebbing of the canalicular hepatocyte membrane as an early response after bile duct ligation (Gupta et al., 2017). This is followed by subsequent separation and bile discharge into blood via the sinusoidal membrane. Others (Rahner et al., 1996) have illustrated para-cellular leakage of bile due to leakiness of the tight junctions. Both mechanisms were not observed in the recent intravital imaging study of (Ghallab et al., 2018), which shows that apical membrane rupture leads to hepatocyte killing, and thereby creating a shunt between bile canaliculi and blood sinusoids. 


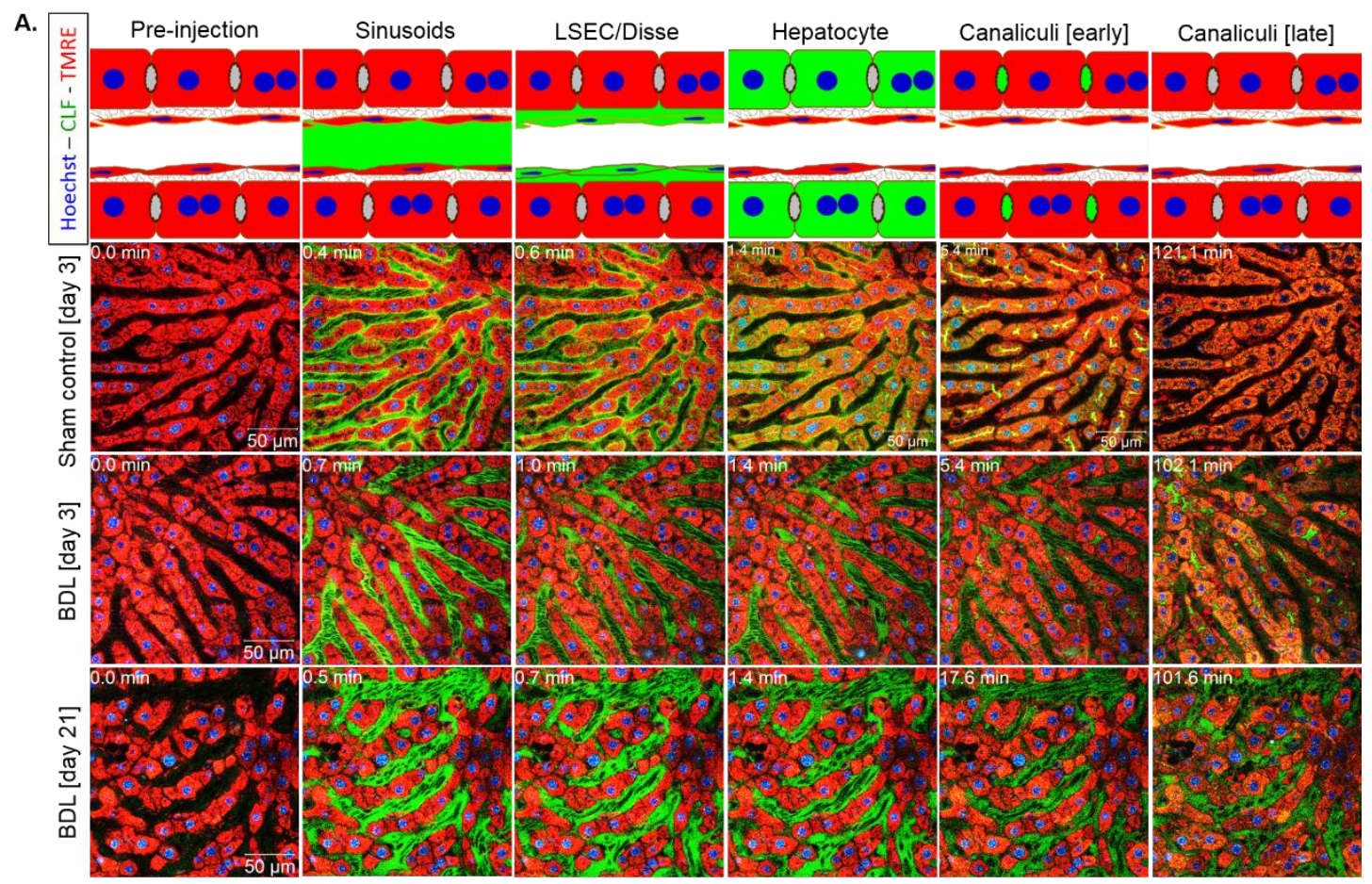

B.

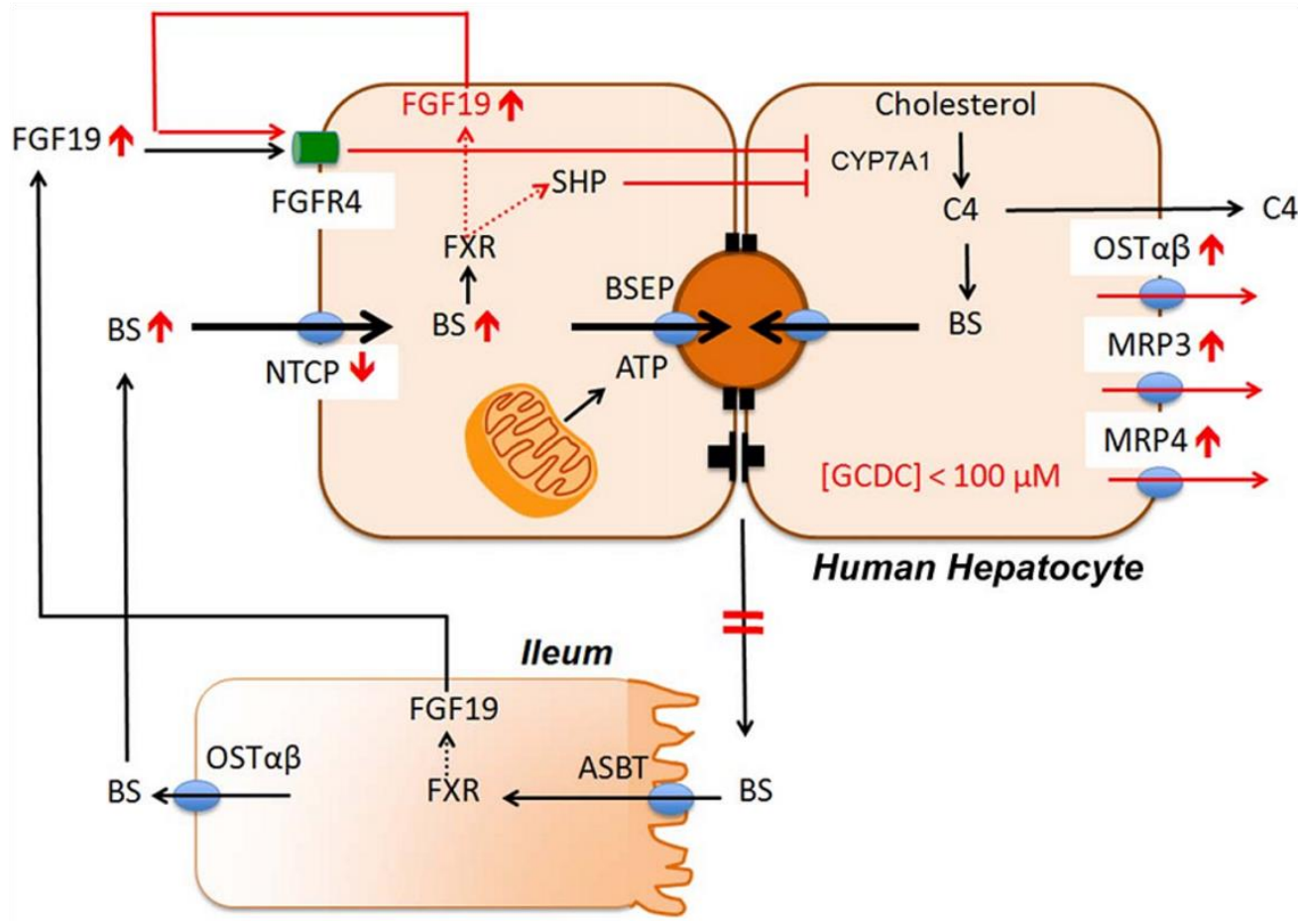

Figure 3. Cholestasis-induced adaptation of transporter and enzyme expression. A. Stills of intravital imaging showing efficient uptake and secretion of the green fluorescent bile salt analogue CLF in controls. In contrast, the uptake from blood is strongly reduced after bile duct ligation, particularly on day 21 . B. A schedule summarizing the adaptive changes at the transporter and enzyme expression level in cholestasis. [Source: Ghallab et al., 2018; Jansen et al., 2017]. 


\section{Conclusions}

Intravital imaging of cholestatic livers revealed that rupture of the apical hepatocyte membrane is the key event that leads to bile infarct information. Furthermore, the time resolved events (summarized in Figure 4) in the acute and the chronic phase after bile duct ligation should be considered during cholestatic liver disease treatment. Although all discussed mechanisms aim at protecting the liver against bile salt accumulation, this results in sharp elevation of bile salt concentrations in the blood. Therefore, the impact of this challenge on other body organs, particularly the kidneys, requires further detailed studies.
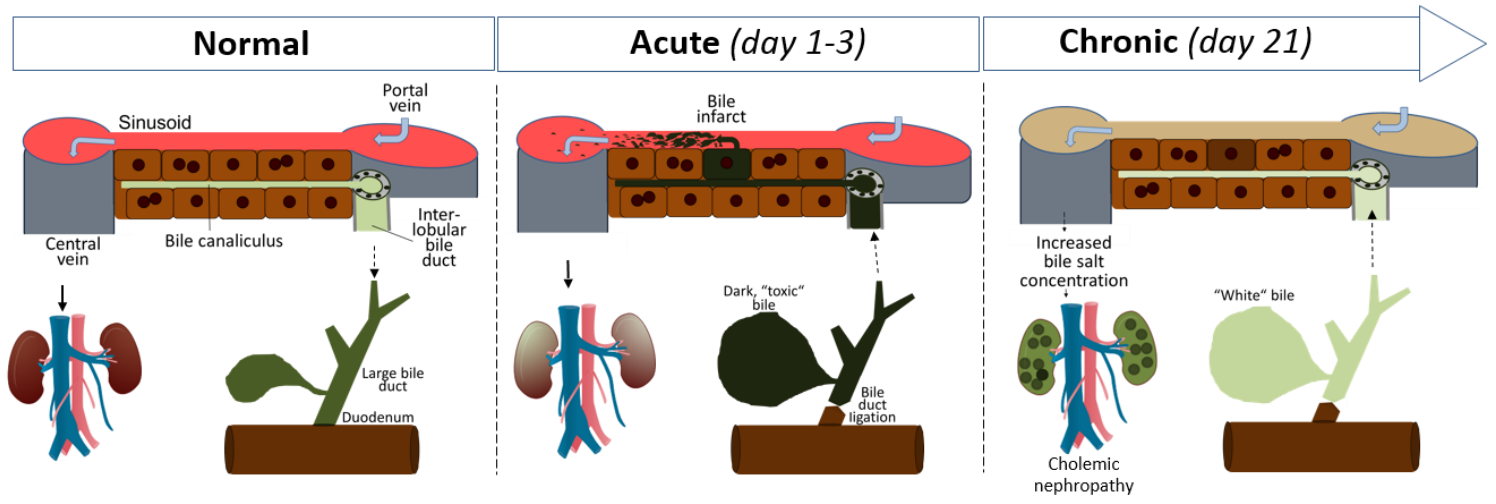

AST, ALT

AP, blood

$B S$ and $B R$

bile

blood

urine

Creatinine, urea

blood

urine

Figure. 4. Mechanism of bile infarct formation. The schedule shows the rupture of the apical hepatocyte membrane on days 1 to 3 post bile duct ligation, as a key event on bile infarct formation, and the subsequent systemic changes. ALT: alanine transaminase; AST: aspartate transaminase; AP: alkaline phosphatase; BS: bile salts; BR: total bilirubin. [Source: Ghallab et al. 2018]

\section{References}

Allen, K., Jaeschke, H. \& Copple, B. L. 2011. Bile Acids Induce Inflammatory Genes In Hepatocytes: A Novel Mechanism Of Inflammation During Obstructive Cholestasis. Am J Pathol, 178, 175-86.

Beuers, U., Maroni, L. \& Elferink, R. O. 2012. The Biliary $\operatorname{Hco}(3)(-)$
Umbrella: Experimental Evidence Revisited. Curr Opin Gastroenterol, 28, 253-7.

Boyer, J. L. 2013. Bile Formation And Secretion. Compr Physiol, 3, 103578.

Cai, S. Y. \& Boyer, J. L. 2018. Bile Infarcts - New Insights Into The Pathogenesis Of Obstructive Cholestasis. Hepatology. 
Cai, S. Y., Ouyang, X., Chen, Y., Soroka, C. J., Wang, J., Mennone, A., Wang, Y., Mehal, W. Z., Jain, D. \& Boyer, J. L. 2017. Bile Acids Initiate Cholestatic Liver Injury By Triggering A Hepatocyte-Specific Inflammatory Response. Jci Insight, 2, E90780.

Chang, J. C., Go, S., De Waart, D. R., Munoz-Garrido, P., Beuers, U., Paulusma, C. C. \& Oude Elferink, R. 2016. Soluble Adenylyl Cyclase Regulates Bile Salt-Induced Apoptosis In Human Cholangiocytes. Hepatology, 64, 522-34.

Chen, W., Owsley, E., Yang, Y., Stroup, D. \& Chiang, J. Y. 2001. Nuclear Receptor-Mediated Repression Of Human Cholesterol 7alphaHydroxylase Gene Transcription By Bile Acids. J Lipid Res, 42, 1402-12.

Coleman, R., Iqbal, S., Godfrey, P. P. \& Billington, D. 1979. Membranes And Bile Formation. Composition Of Several Mammalian Biles And Their Membrane-Damaging Properties. Biochem J, 178, 201-8.

Das, A., Yaqoob, U., Mehta, D. \& Shah, V. H. 2009. Fxr Promotes Endothelial Cell Motility Through Coordinated Regulation Of Fak And Mmp-9. Arterioscler Thromb Vasc Biol, 29, 562-70.

De Aguiar Vallim, T. Q., Tarling, E. J. \& Edwards, P. A. 2013. Pleiotropic Roles Of Bile Acids In Metabolism. Cell Metab, 17, 657-69.

Fickert, P. \& Wagner, M. 2017. Biliary Bile Acids In Hepatobiliary Injury What Is The Link? J Hepatol, 67, 619-631.

Geier, A., Wagner, M., Dietrich, C. G. \& Trauner, M. 2007. Principles Of Hepatic Organic Anion Transporter
Regulation During Cholestasis, Inflammation And Liver Regeneration. Biochim Biophys Acta, 1773, 283-308.

Ghallab, A., Celliere, G., Henkel, S. G., Driesch, D., Hoehme, S., Hofmann, U., Zellmer, S., Godoy, P., Sachinidis, A., Blaszkewicz, M., Reif, R., Marchan, R., Kuepfer, L., Haussinger, D., Drasdo, D., Gebhardt, R. \& Hengstler, J. G. 2016. Model-Guided Identification Of A Therapeutic Strategy To Reduce Hyperammonemia In Liver Diseases. J Hepatol, 64, 860-71.

Ghallab, A., Hengstler, J.G. 2018. Liver Regeneration And New Technical Possibilities By Two-Photon Based Intravital Imaging. $\quad S v u$ International Journal of Veterinary Sciences, 1, 4-15.

Ghallab, A., Hofmann, U., Sezgin, S., Vartak, N., Hassan, R., Zaza, A., Godoy, P., Schneider, K. M., Guenther, G., Ahmed, Y. A., Abbas, A. A., Keitel, V., Kuepfer, L., Dooley, S., Lammert, F., Trautwein, C., Spiteller, M., Drasdo, D., Hofmann, A. F., Jansen, P. L. M., Hengstler, J. G. \& Reif, R. 2018. Bile Microinfarcts In Cholestasis Are Initiated By Rupture Of The Apical Hepatocyte Membrane And Cause Shunting Of Bile To Sinusoidal Blood. Hepatology.

Gujral, J. S., Farhood, A., Bajt, M. L. \& Jaeschke, H. 2003. Neutrophils Aggravate Acute Liver Injury During Obstructive Cholestasis In Bile Duct-Ligated Mice. Hepatology, 38, 355-63.

Gupta, K., Li, Q., Fan, J. J., Fong, E. L. S., Song, Z., Mo, S., Tang, H., Ng, I. C., Ng, C. W., Pawijit, P., Zhuo, S., Dong, C. Y., Low, B. C., Wee, 
A., Dan, Y. Y., Kanchanawong, P., So, P., Viasnoff, V.\& Yu, H. 2017. Actomyosin Contractility Drives Bile Regurgitation As An Early Response During Obstructive Cholestasis. J Hepatol, 66, 12311240.

Jansen, P. L., Ghallab, A., Vartak, N., Reif, R., Schaap, F. G., Hampe, J. \& Hengstler, J. G. 2017. The Ascending Pathophysiology Of Cholestatic Liver Disease. Hepatology, 65, 722-738.

Koppert, S., Buscher, A., Babler, A., Ghallab, A., Buhl, E. M., Latz, E., Hengstler, J. G., Smith, E. R. \& Jahnen-Dechent, W. 2018. Cellular Clearance And Biological Activity Of Calciprotein Particles Depend On Their Maturation State And Crystallinity. Front Immunol, 9, 1991.

Leist, M., Ghallab, A., Graepel, R., Marchan, R., Hassan, R., Bennekou, S. H., Limonciel, A., Vinken, M., Schildknecht, S., Waldmann, T., Danen, E., Van Ravenzwaay, B., Kamp, H., Gardner, I., Godoy, P., Bois, F. Y., Braeuning, A., Reif, R., Oesch, F., Drasdo, D., Hohme, S., Schwarz, M., Hartung, T., Braunbeck, T., Beltman, J., Vrieling, H., Sanz, F., Forsby, A., Gadaleta, D., Fisher, C., Kelm, J., Fluri, D., Ecker, G., Zdrazil, B., Terron, A., Jennings, P., Van Der Burg, B., Dooley, S., Meijer, A. H., Willighagen, E., Martens, M., Evelo, C., Mombelli, E., Taboureau, O., Mantovani, A., Hardy, B., Koch, B., Escher, S., Van Thriel, C., Cadenas, C., Kroese, D., Van De Water, B. \& Hengstler, J. G. 2017. Adverse Outcome Pathways: Opportunities,
Limitations And Open Questions. Arch Toxicol, 91, 3477-3505.

Liu, X., Zhang, X., Ji, L., Gu, J., Zhou, M. \& Chen, S. 2015. Farnesoid X Receptor Associates With BetaCatenin And Inhibits Its Activity In Hepatocellular Carcinoma. Oncotarget, 6, 4226-38.

Masyuk, T. V., Ritman, E. L. \& Larusso, N. F. 2001. Quantitative Assessment Of The Rat Intrahepatic Biliary System By Three-Dimensional

Reconstruction. Am J Pathol, 158, 2079-88.

Norlin, M. \& Wikvall, K. 2007. Enzymes In The Conversion Of Cholesterol Into Bile Acids. Curr Mol Med, 7, 199-218.

Puglielli, L., Amigo, L., Arrese, M., Nunez, L., Rigotti, A., Garrido, J., Gonzalez, S., Mingrone, G., Greco, A. V., Accatino, L. \& Et Al. 1994. Protective Role Of Biliary Cholesterol And Phospholipid Lamellae Against Bile AcidInduced Cell Damage. Gastroenterology, 107, 244-54.

Rahner, C., Stieger, B. \& Landmann, L. $1996 . \quad$ Structure-Function Correlation Of Tight Junctional Impairment After Intrahepatic And Extrahepatic Cholestasis In Rat Liver. Gastroenterology, 110, 1564-78.

Reif, R., Ghallab, A., Beattie, L., Gunther, G., Kuepfer, L., Kaye, P. M. \& Hengstler, J. G. 2017. In Vivo Imaging Of Systemic Transport And Elimination Of Xenobiotics And Endogenous Molecules In Mice. Arch Toxicol, 91, 1335-1352.

Rolleston, H. D. 1905. Diseases Of The Liver, Gall-Bladder And BileDucts Philadelphia : Saunders. 
Russell, D. W. 2003. The Enzymes, Regulation, And Genetics Of Bile Acid Synthesis. Annu Rev Biochem, 72, 137-74.

Schaap, F. G., Van Der Gaag, N. A., Gouma, D. J. \& Jansen, P. L. 2009. High Expression Of The Bile SaltHomeostatic Hormone Fibroblast Growth Factor 19 In The Liver Of Patients With Extrahepatic Cholestasis. Hepatology, 49, 122835.

Schliess, F., Hoehme, S., Henkel, S. G., Ghallab, A., Driesch, D., Bottger, J., Guthke, R., Pfaff, M., Hengstler, J. G., Gebhardt, R., Haussinger, D., Drasdo, D. \& Zellmer, S. 2014. Integrated Metabolic SpatialTemporal Model For The Prediction Of Ammonia Detoxification During Liver Damage And Regeneration. Hepatology, 60, 2040-51.

Schneider, K. M., Albers, S. \& Trautwein, C. 2018. Role Of Bile Acids In The Gut-Liver Axis. $J$ Hepatol, 68, 1083-1085.

Schoemaker, M. H., Conde De La Rosa, L., Buist-Homan, M., Vrenken, T. E., Havinga, R., Poelstra, K., Haisma, H. J., Jansen, P. L. \& Moshage, $\mathrm{H}$ 2004. Tauroursodeoxycholic Acid Protects Rat Hepatocytes From Bile Acid-Induced Apoptosis Via Activation Of Survival Pathways. Hepatology, 39, 1563-73.

Schreuder, T. C., Marsman, H. A., Lenicek, M., Van Werven, J. R., Nederveen, A. J., Jansen, P. L. \&
Schaap, F. G. 2010. The Hepatic Response To Fgf19 Is Impaired In Patients With Nonalcoholic Fatty Liver Disease And Insulin Resistance. Am J Physiol Gastrointest Liver Physiol, 298, G440-5.

Slitt, A. L., Allen, K., Morrone, J., Aleksunes, L. M., Chen, C., Maher, J. M., Manautou, J. E., Cherrington, N. J. \& Klaassen, C. D. 2007. Regulation Of Transporter Expression In Mouse Liver, Kidney, And Intestine During Extrahepatic Cholestasis. Biochim Biophys Acta, 1768, 637-47.

Tag, C. G., Sauer-Lehnen, S., Weiskirchen, S., BorkhamKamphorst, E., Tolba, R. H., Tacke, F. \& Weiskirchen, R. 2015. Bile Duct Ligation In Mice: Induction Of Inflammatory Liver Injury And Fibrosis By Obstructive Cholestasis. J Vis Exp.

Woolbright, B. L., Dorko, K., Antoine, D. J., Clarke, J. I., Gholami, P., Li, F., Kumer, S. C., Schmitt, T. M., Forster, J., Fan, F., Jenkins, R. E., Park, B. K., Hagenbuch, B., Olyaee, M. \& Jaeschke, H. 2015. Bile Acid-Induced Necrosis In Primary Human Hepatocytes And In Patients With Obstructive Cholestasis. Toxicol Appl Pharmacol, 283, 168-77.

Author names in bold designate shared co-first/senior authorship. 